\title{
Evaluating the Efficiency of School Preceptors by Fuzzy Risk Analysis
}

\author{
Rasoul Saneifard ${ }^{1}$ and Rahim Saneifard ${ }^{2}$ \\ ${ }^{1}$ Department of Engineering Technology, Texas Southern University, Houston, TX 77004, USA \\ ${ }^{2}$ Department of Mathematics, Urmia Branch, Islamic Azad University, Urmia, Iran
}

Correspondence should be addressed to Rasoul Saneifard; rsaneifard@hotmail.com

Received 26 January 2013; Accepted 13 March 2013

Academic Editor: Tofigh Allahviranloo

Copyright (c) 2013 R. Saneifard and R. Saneifard. This is an open access article distributed under the Creative Commons Attribution License, which permits unrestricted use, distribution, and reproduction in any medium, provided the original work is properly cited.

\begin{abstract}
This paper presents a new method for evaluating the efficiency of school preceptors based on fuzzy number arithmetic operations. It uses fuzzy numbers to represent fuzzy grades. The fuzzy weights of criteria are automatically generated from the opinions of evaluators. The simplified fuzzy number arithmetic operations are used for calculating the average of fuzzy numbers. It can evaluate the efficiency of school preceptors in a more flexible and more intelligent manner.
\end{abstract}

\section{Introduction}

The ranking of fuzzy numbers has been a concern in fuzzy Multiple Attribute Decision Making since its inception. More than 20 fuzzy ranking indices have been proposed since 1976. Various techniques are applied to compare the fuzzy numbers. Some of these ranking methods have been compared and reviewed by Bortolan and Degani [1]. Chen and Hwang [2] thoroughly reviewed the existing approaches and pointed out some illogical conditions that arise among them. Among the existing ranking methods, centroid index methods are extensively studied and applied to many decision making problems. Recently, S. J. Chen and S. M. Chen [3] point outed the drawback of the existing centroid index ranking methods and proposed a new centroid index method for ranking fuzzy numbers based on the Center of Gravity (COG) point. They applied the COG based ranking method to a human selection problem based on Fuzzy Number Induced Order Weighted Averaging operator (2003). However, the COG based ranking method presented by S. J. Chen and S. M. Chen [3] still has some drawbacks, that is, it cannot correctly calculate the ranking order of the generalized fuzzy numbers in some situations. Also, Chang et al. [4] established the criteria for high school preceptor appraisal. They used fuzzy linguistic questionnaires to evaluate the efficiency of high school preceptors and they used fuzzy linguistic integrating techniques to calculate preceptor's fuzzy grades, and then used Lee and Li's method to rank preceptors' fuzzy grades. Because Chang et al.'s methods have drawbacks in preceptors' appraisal, it is necessary to develop a new method to overcome these drawbacks.

In this paper, we propose a new centroid index method for ranking fuzzy numbers. First we briefly introduce some existing centroid index ranking methods of fuzzy numbers. Then we propose a new method to evaluate the efficiency of school preceptors based on fuzzy number arithmetic operations. The proposed method can overcome the drawbacks of the other methods.

\section{The Centroid Formulae for Fuzzy Numbers}

A fuzzy number is a convex fuzzy subset of the real line $R$ and is completely defined by its membership function. Let $A$ be a fuzzy number, whose membership function $f_{A}(x)$ can generally be defined as [5-9],

$$
f_{A}(x)= \begin{cases}f_{A}^{L}(x) & \text { when } a_{1} \leq x \leq a_{2} \\ \omega & \text { when } a_{2} \leq x \leq a_{3} \\ f_{A}^{R}(x) & \text { when } a_{3} \leq x \leq a_{4} \\ 0, & \text { otherwise }\end{cases}
$$


where $0 \leq \omega \leq 1$ is a constant, $f_{A}^{L}:\left[a_{1}, a_{2}\right] \rightarrow[0, \omega]$ and $f_{A}^{R}:\left[a_{3}, a_{4}\right] \rightarrow[0, \omega]$ are two strictly monotonically and continuous mappings from $R$ to closed interval $[0, \omega]$. When $\omega=1$, then $A$ is a normal fuzzy number; otherwise, it is said to be a nonnormal fuzzy number. If the membership function $f_{A}(x)$ is piecewise linear, then $A$ is referred to as a trapezoidal fuzzy number and is usually denoted by, $A=$ $\left(a_{1}, a_{2}, a_{3}, a_{4} ; \omega\right)$. In particular, if $a_{2}=a_{3}$, the trapezoidal fuzzy number is reduced to a triangular fuzzy number. Since $f_{A}^{L}(x)$ and $f_{A}^{R}(x)$ are both strictly monotonically and continuous functions, their inverse functions exist and should also be continuous and strictly monotonically. Let $g_{A}^{L}:[0, \omega] \rightarrow$ $\left[a_{1}, a_{2}\right]$ and $g_{A}^{R}:[0, \omega] \rightarrow\left[a_{3}, a_{4}\right]$ be the inverse functions of $f_{A}^{L}$ and $f_{A}^{R}$, respectively. Then $g_{A}^{L}(y)$ and $g_{A}^{R}(y)$ should be integrable on the closed interval $[0, \omega]$. In other words, both $\int_{0}^{\omega} g_{A}^{L}(y) d y$ and $\int_{0}^{\omega} g_{A}^{R}(y) d y$ should exist. In the case of trapezoidal fuzzy number, the inverse function $g_{A}^{L}(y)$ and $g_{A}^{R}(y)$ can be analytically expressed as

$$
\begin{array}{ll}
g_{A}^{L}(y)=a_{1}+\frac{\left(a_{2}-a_{1}\right) y}{\omega}, & 0 \leq y \leq \omega, \\
g_{A}^{R}(y)=a_{4}-\frac{\left(a_{4}-a_{3}\right) y}{\omega}, & 0 \leq y \leq \omega .
\end{array}
$$

In order to determine the centroid point $\left(\bar{x}_{0}, \bar{y}_{0}\right)$ of a fuzzy number $A$, Wang et al. [10] provided the following centroid formulae:

$$
\begin{gathered}
\bar{x}_{0}(A)=\frac{\int_{a_{1}}^{a_{2}} x f_{A}^{L}(x) d x+\int_{a_{2}}^{a_{3}}(x \omega) d x+\int_{a_{3}}^{a_{4}} x f_{A}^{R}(x) d x}{\int_{a_{1}}^{a_{2}} f_{A}^{L}(x) d x+\int_{a_{2}}^{a_{3}}(\omega) d x+\int_{a_{3}}^{a_{4}} f_{A}^{R}(x) d x}, \\
\bar{y}_{0}(A)=\frac{\int_{0}^{\omega} y\left(g_{A}^{R}(y)-g_{A}^{L}(y)\right) d y}{\int_{0}^{\omega}\left(g_{A}^{R}(y)-g_{A}^{L}(y)\right) d y} .
\end{gathered}
$$

The ranking value $R(A)$ of the fuzzy number $A$ is defined as follows [11]:

$$
R(A)=\sqrt{\bar{x}_{0}^{2}(A)+\bar{y}_{0}^{2}(A)} .
$$

The larger the value $R(A)$, the better the ranking of $A$.

In [12], the authors presented a centroid-index ranking method for ordering fuzzy numbers. The centroid point of a fuzzy number $A$ is $\left(\bar{x}_{A}, \bar{y}_{A}\right)$, where $\bar{x}_{A}$ and $\bar{y}_{A}$ are the same as formula (2.2) and (2.3) in [12]. The ranking value $S(A)$ of the fuzzy number $A$ is defined as follows:

$$
S(A)=\bar{x}_{A} \times \bar{y}_{A} .
$$

The larger the value $S(A)$, the better the ranking of $A$. In [3], S. J. Chen and S. M. Chen proposed a simple method to obtain COG point of fuzzy numbers. If $A$ is a generalized

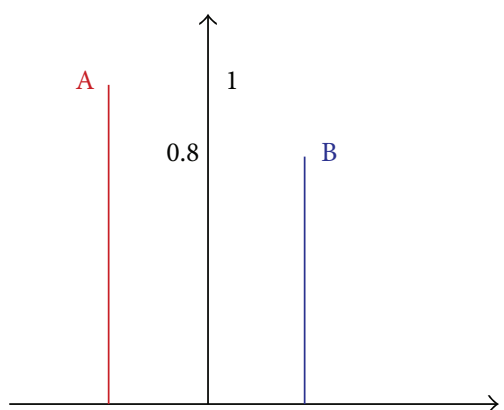

Figure 1

fuzzy number, where $A=\left(a_{1}, a_{2}, a_{3}, a_{4} ; w\right)$, then the COG point $\left(x_{A}^{*}, y_{A}^{*}\right)$ of $A$ is as follows:

$$
\begin{gathered}
x_{A}^{*}=\frac{y_{A}^{*}\left(a_{2}+a_{3}\right)+\left(a_{1}+a_{4}\right)\left(1-y_{A}^{*}\right)}{2}, \\
y_{A}^{*}= \begin{cases}\frac{\omega\left(\left(a_{3}-a_{2}\right) /\left(a_{4}-a_{1}\right)+2\right)}{6}, & a_{1} \neq a_{4}, \\
\frac{1}{2}, & a_{1}=a_{4} .\end{cases}
\end{gathered}
$$

After obtaining the COG point of fuzzy number $A$, where $A=\left(a_{1}, a_{2}, a_{3}, a_{4} ; w_{A}\right)$, the ranking value $\operatorname{Rank}(A)$ can be calculated as

$$
\operatorname{Rank}(A)=x_{A}^{*}+\left(w_{A}-y_{A}^{*}\right)^{\widehat{s}_{A}} \times\left(y_{A}^{*}+0.5\right)^{1-w_{A}},
$$

where

$$
\begin{aligned}
& \widehat{s}_{A}=\sqrt{\frac{\sum_{i=1}^{4}\left(a_{i}-\bar{a}\right)^{2}}{3}}, \\
& \bar{a}=\frac{a_{1}+a_{2}+a_{3}+a_{4}}{4} .
\end{aligned}
$$

The larger the value $\operatorname{Rank}(A)$, the better the ranking $A$. However, this method has a drawback in that it cannot correctly rank generalized fuzzy numbers in some situations. The example is used to show the drawback Chen's method.

Example 1. Two generalized fuzzy number $A$ and $B$ are shown as follows (Figure 1):

$$
\begin{gathered}
A=(-0.01,-0.01,-0.01,-0.01 ; 1), \\
B=(0.01,0.01,0.01,0.01 ; 0.8) .
\end{gathered}
$$

It can be easily to obtain the COG points of fuzzy numbers $A$ and $B$, respectively, as follows, $\left(x_{A}^{*}, y_{A}^{*}\right)=(-0.01,0.5)$ and $\left(x_{B}^{*}, y_{B}^{*}\right)=(0.01,0.4)$. By applying Chen method, we have $R(A)=0.99$ and $R(B)=0.989$. The ranking result shows that ranking order is $A>B$. However, it can be easily seen that the correct order is $A \prec B$.

To compensate for these shortcomings, a new index of ranking fuzzy numbers is constructed in this article. 


\section{A New Ranking Method for Generalized Fuzzy Numbers}

In this section, the authors propose a novel technique for ranking of fuzzy numbers based on the distance method. The new method not only considers the centroid point of fuzzy numbers, but also considers the min crisp value of a fuzzy number.

Assume that there are $n$ generalized fuzzy numbers $A_{1}, A_{2}, \ldots, A_{n}$, where $A_{j}=\left(a_{1 j}, a_{2 j}, a_{3 j}, a_{4 j} ; w_{A_{j}}\right), 1 \leq j \leq n$, $0<w_{A_{j}} \leq 1,0 \leq a_{1 j} \leq a_{2 j} \leq a_{3 j} \leq a_{4 j} \leq k, k$ is any real value. The value $w_{A_{j}}$ denotes the maximum membership value of the generalized trapezoidal fuzzy number $A_{j}$, where $1 \leq j \leq n$. The proposed method for ranking fuzzy numbers $A_{1}, A_{2}, \ldots, A_{n}$ is now presented as follows.

Step 1. For each generalized trapezoidal fuzzy number $A_{j}$, where $1 \leq j \leq n$, if the fuzzy number $A_{j}$ is not a standardized generalized trapezoidal fuzzy number, where the universe of discourse of the generalized trapezoidal fuzzy number $A_{j}$ is $[0, k]$, then translate the generalized trapezoidal fuzzy number $A_{j}=\left(a_{1 j}, a_{2 j}, a_{3 j}, a_{4 j} ; w_{A_{j}}\right)$ into a standardized generalized trapezoidal fuzzy number $A_{j}^{*}$ shown as follows:

$$
A_{j}^{*}=\left(\frac{a_{1 j}}{k}, \frac{a_{2 j}}{k}, \frac{a_{3 j}}{k}, \frac{a_{4 j}}{k} ; w_{A_{j}^{*}}\right)=\left(a_{1 j}^{*}, a_{2 j}^{*}, a_{3 j}^{*}, a_{4 j}^{*} ; w_{A_{j}^{*}}\right),
$$

where $w_{A_{j}}=w_{A_{j}^{*}}, 0<w_{A_{j}^{*}} \leq 1,0 \leq a_{1 j}^{*} \leq a_{2 j}^{*} \leq a_{3 j}^{*} \leq a_{4 j}^{*} \leq 1$ or $-1 \leq a_{1 j}^{*} \leq a_{2 j}^{*} \leq a_{3 j}^{*} \leq a_{4 j}^{*} \leq 1$ and $1 \leq j \leq n$.

Step 2. Use formula (6) to calculate the centroid point $\left(x_{A_{j}^{*}}^{*}, y_{A_{j}^{*}}^{*}\right)$ of each standardized generalized trapezoidal fuzzy number $A_{j}^{*}$, where $1 \leq j \leq n$.

Step 3. Calculate the standard deviation $s_{A_{j}^{*}}$ of each standardized generalized trapezoidal fuzzy number $A_{j}^{*}$ from (8). The standard deviation $s_{A_{j}^{*}}$ indicates the degree of dispersion of the standardized generalized trapezoidal fuzzy number $A_{j}^{*}$, where $1 \leq j \leq n$.

Step 4. Use the standard deviation $s_{A_{j}^{*}}$ and $y_{A_{j}^{*}}^{*}$ of the centroid point $\left(x_{A_{j}^{*}}^{*}, y_{A_{j}^{*}}^{*}\right)$ to derive a new value $y_{A_{j}^{*}}^{* \widehat{s}}$ shown as follows:

$$
y_{A_{j}^{*}}^{* \widehat{s}}=\left(w_{A_{j}^{*}}-y_{A_{j}^{*}}^{*}\right)^{\widehat{s}_{A_{j}^{*}}} \times\left(y_{A_{j}^{*}}^{*}+0.5\right)^{1-w_{A_{j}^{*}}},
$$

where $1 \leq j \leq n$, to obtain a new point $\left(x_{A_{j}^{*}}^{*}, y_{A_{j}^{*}}^{* \widehat{s}}\right)$.

Step 5. Use the new point $\left(x_{A_{j}^{*}}^{*}, y_{A_{j}^{*}}^{* s}\right)$ to calculate the ranking value $S\left(A_{j}^{*}\right)$ of the fuzzy numbers $A_{j}^{*}$ as follows:

$$
\begin{aligned}
S\left(A_{j}^{*}\right) & =\left[\left(x_{A_{j}^{*}}^{*}-a_{\min }\right)^{2}+\left(y_{A_{j}^{*}}^{* \widehat{s}}-0\right)^{2}\right]^{1 / 2} \\
& =\left[\left(x_{A_{j}^{*}}^{*}-a_{\min }\right)^{2}+\left(y_{A_{j}^{*}}^{* \widehat{s}}\right)^{2}\right]^{1 / 2}
\end{aligned}
$$

where $a_{\text {min }}$ denotes the minimum value of the $a_{1 j}, a_{2 j}, a_{3 j}$ and $a_{4 j}$, and $1 \leq j \leq n$. From formula (12), we can see that $S\left(A_{j}^{*}\right)$ can be considered as the Euclidean distance between the point $\left(x_{A_{j}^{*}}^{*}, y_{A_{j}^{*}}^{* \widehat{s}}\right)$ and the point $\left(a_{\min }, 0\right)$. We can say that the larger the value of $S\left(A_{j}^{*}\right)$, the better the ranking of $A_{j}^{*}$, where $1 \leq j \leq n$.

Example 2. As shown above, two generalized fuzzy numbers are shown as follows:

$$
\begin{gathered}
A=(-0.01,-0.01,-0.01,-0.01 ; 1), \\
B=(0.01,0.01,0.01,0.01 ; 0.8) .
\end{gathered}
$$

First, the COG points of the fuzzy numbers $A$ and $B$ can be obtained as follows, respectively.

$$
\begin{gathered}
\left(x_{A^{*}}^{*}, y_{A^{*}}^{*}\right)=(-0.01,0.5), \\
\left(x_{B^{*}}^{*}, y_{B^{*}}^{*}\right)=(0.01,0.4) .
\end{gathered}
$$

Then, translate the COG points of fuzzy numbers $A$ and $B$ into Index point. The results can be shown as follows:

$$
\begin{aligned}
x_{A^{*}}^{*} & =-0.01, \\
y_{A^{*}}^{* s} & =\left(w_{A^{*}}-y_{A^{*}}^{*}\right)^{s_{A^{*}}} \times\left(y_{A^{*}}^{*}+0.5\right)^{1-w_{A^{*}}}=1, \\
x_{B^{*}}^{*} & =0.01, \\
y_{B^{*}}^{* s} & =\left(w_{B^{*}}-y_{B^{*}}^{*}\right)^{s_{B^{*}}} \times\left(y_{B^{*}}^{*}+0.5\right)^{1-w_{B^{*}}}=1 .
\end{aligned}
$$

The ranking value of fuzzy numbers $A$ and $B$ can be calculated, respectively, as follows:

$$
S(A)=1, \quad S(B)=1.0002 .
$$

The ranking order of fuzzy numbers $A$ and $B$ is $B>A$. It can be seen that the proposed method can overcome the drawback of the one presented in [12].

\section{A Method for High School Preceptors Evaluation}

In this section, we present a new method for high school preceptors appraisal, where the criteria and the fuzzy linguistic questionnaires used for preceptor appraisal in [3] are adopted as shown in Tables 1 and 2, respectively. In the fuzzy linguistic questionnaire shown in Table 3, Saneifard et al. used five linguistic levels to evaluate teachers' performance regarding the subcriterion $X_{i j}$, that is, very low (VL), low $(\mathrm{L})$, middle $(\mathrm{M})$, high $(\mathrm{H})$ and very high $(\mathrm{VH})$. They used the triangular fuzzy numbers $\widetilde{1}, \widetilde{2}, \widetilde{3}, \widetilde{4}$, and $\widetilde{5}$ corresponding to the linguistic satisfaction levels $\mathrm{VL}, \mathrm{L}, \mathrm{M}, \mathrm{H}$, and $\mathrm{VH}$, respectively, where $\widetilde{1}=(0,1,2), \widetilde{2}=(1,2,3), \widetilde{3}=(2,3,4)$, $\widetilde{4}=(3,4,5)$, and $\widetilde{5}=(4,5,6)$. The fuzzy grade $G\left(x_{i j}\right)$ of the subcriterion $X_{i j}$ is calculated as follows:

$$
G\left(x_{i j}\right)=\frac{\sum_{k=1}^{5} x_{i j k} f\left(x_{i j k}\right)}{\sum_{k=1}^{5} f\left(x_{i j k}\right)},
$$


TABLE 1: The criteria for evaluating the efficiency of high school preceptors.

\begin{tabular}{|c|c|c|}
\hline Criteria & Subcriteria & Contents \\
\hline \multirow{9}{*}{$X_{1}$ (teaching) } & $X_{11}$ & $\begin{array}{l}\text { According to the standard of the course and the needs } \\
\text { of the students to achieve the teaching goals }\end{array}$ \\
\hline & $X_{12}$ & $\begin{array}{l}\text { To make teaching plans and to prepare teaching } \\
\text { materials and tools properly }\end{array}$ \\
\hline & $X_{13}$ & $\begin{array}{l}\text { To present teaching materials clearly and correctly with } \\
\text { proper methods }\end{array}$ \\
\hline & $X_{14}$ & $\begin{array}{l}\text { To bring the motivation of learning and testing and to } \\
\text { increase students' attention on lessons }\end{array}$ \\
\hline & $X_{15}$ & $\begin{array}{l}\text { To express clearly in speaking (helpful for } \\
\text { comprehension and learning) }\end{array}$ \\
\hline & $X_{16}$ & $\begin{array}{l}\text { To express clearly in writing (helpful for } \\
\text { comprehension and learning) }\end{array}$ \\
\hline & $X_{17}$ & $\begin{array}{l}\text { To make good use of various teaching methods and } \\
\text { teaching media }\end{array}$ \\
\hline & $X_{18}$ & To make good use of time while teaching \\
\hline & $X_{19}$ & Giving proper feedback to students while teaching \\
\hline \multirow{5}{*}{$X_{2}$ (class managing) } & $X_{21}$ & $\begin{array}{l}\text { Counseling students to obey the rules of life and } \\
\text { develop good habits }\end{array}$ \\
\hline & $X_{22}$ & $\begin{array}{l}\text { To direct students to keep personal and public } \\
\text { sanitation }\end{array}$ \\
\hline & $X_{23}$ & Management of classroom \\
\hline & $X_{24}$ & Establishing an appropriate rule of class \\
\hline & $X_{25}$ & To praise and punish students properly \\
\hline \multirow{4}{*}{$X_{3}$ (professional attitude) } & $X_{31}$ & To take care of students actively \\
\hline & $X_{32}$ & Working hard \\
\hline & $X_{33}$ & Researching and pursuing further education \\
\hline & $X_{34}$ & Being enthusiastic with working \\
\hline \multirow{6}{*}{$X_{4}$ (cooperation in administration) } & $X_{41}$ & To build various kinds of students' files \\
\hline & $X_{42}$ & To join activities of school actively \\
\hline & $X_{43}$ & To keep good relationship with coworkers in school \\
\hline & $X_{44}$ & $\begin{array}{l}\text { To keep good relationship and interactions with } \\
\text { students' parents }\end{array}$ \\
\hline & $X_{45}$ & Treating students fairly \\
\hline & $X_{46}$ & To keep good relationship with students \\
\hline \multirow{4}{*}{$X_{5}$ (ability to use computers) } & $X_{51}$ & To be able to send and receive email \\
\hline & $X_{52}$ & $\begin{array}{l}\text { To be able to design a web page interacting with } \\
\text { students }\end{array}$ \\
\hline & $X_{53}$ & $\begin{array}{l}\text { To be able to use word edit software to edit handouts } \\
\text { and test papers }\end{array}$ \\
\hline & $X_{54}$ & $\begin{array}{l}\text { To be able to search data on the web to be used in } \\
\text { teaching }\end{array}$ \\
\hline
\end{tabular}

where $i$ denotes the index of the criterion, $j$ denotes the index of the subcriterion, $k$ denotes the index of linguistic levels, $x_{i j k}$ denotes the $k$ th linguistic satisfaction level of the criterion $X_{i j}, 1 \leq k \leq 5, x_{i j k} \in\{\tilde{1}, \widetilde{2}, \widetilde{3}, \widetilde{4}, \widetilde{5}\}, f\left(x_{i j k}\right)$ denotes the degree that the teacher satisfies the $k$ th satisfaction level of the criterion $X_{i j}$, and $\sum_{k=1}^{5} f\left(x_{i j k}\right)=1$. Saneifard et al. also used fuzzy linguistic questionnaires to determine the weight of a criterion. A fuzzy linguistic questionnaire for determining the weights of a criterion is shown in Table 3. The fuzzy weight $W\left(x_{i}\right)$ of the criterion $X_{i}$ is calculated as follows:

$$
W\left(x_{j}\right)=\frac{\sum_{k=1}^{5} x_{i k} f\left(x_{i k}\right)}{\sum_{k=1}^{5} f\left(x_{i k}\right)},
$$


TABLE 2: A fuzzy linguistic questionnaire for evaluating the efficiency of a preceptor.

\begin{tabular}{|c|c|c|c|c|}
\hline \multicolumn{5}{|c|}{$\begin{array}{l}\text { Fuzzy linguistic questionnaire-satisfaction levels of } \\
\text { the criterion } X_{i j}\end{array}$} \\
\hline Low & & & & High \\
\hline$\leftarrow$ & & & & $\rightarrow$ \\
\hline VL & $\mathrm{L}$ & M & $\mathrm{H}$ & VH \\
\hline $0 \%$ & $0 \%$ & $0 \%$ & $60 \%$ & $40 \%$ \\
\hline
\end{tabular}

TABLE 3: A fuzzy linguistic questionnaire for determining the weight of the criterion $X_{i}$.

\begin{tabular}{|c|c|c|c|c|}
\hline \multicolumn{5}{|c|}{$\begin{array}{l}\text { Fuzzy linguistic questionnaire-Importance levels of } \\
\text { the criterion } X_{i}\end{array}$} \\
\hline Low & & & & High \\
\hline$\leftarrow$ & & & & $\rightarrow$ \\
\hline VL & $\mathrm{L}$ & $\mathrm{M}$ & $\mathrm{H}$ & VH \\
\hline $0 \%$ & $0 \%$ & $0 \%$ & $60 \%$ & $40 \%$ \\
\hline
\end{tabular}

where $i$ denotes the index of the criterion, $k$ denotes the index of linguistic levels, $x_{i k}$ denotes the $k$ th importance level of the criterion $X_{i}, 1 \leq k \leq 5, x_{i k} \in\{\tilde{1}, \widetilde{2}, \widetilde{3}, \widetilde{4}, \widetilde{5}\}, f\left(x_{i k}\right)$ denotes the degree of percentage that the criterion $X_{i}$ satisfies the $k$ th importance level, and $\sum_{k=1}^{5} f\left(x_{i j k}\right)=1$. The proposed method for high school preceptors appraisal is now presented as follows.

Step 1. Determine the fuzzy weight of each criterion. Let each evaluator use the fuzzy linguistic questionnaire shown in Table 3 to evaluate the importance of each criterion. Then, use (19) to calculate the fuzzy weight of each criterion evaluated by each evaluator, where a fuzzy weight represented by a triangular fuzzy number $(k, m, n)$ should satisfy the rules.

If $k<1$, then let $k=1$; if $n>5$, then let $n=5$. For example, assume that there are five evaluators $E_{1}, E_{2}, E_{3}, E_{4}$, $E_{5}$ and nine preceptors $A_{1}, A_{2}, A_{3}, A_{4}, A_{5}, A_{6}, A_{7}, A_{8}, A_{9}$ being evaluated. After the five evaluators fill out the fuzzy linguistic questionnaires, we get the result shown in Table 4 . After applying (19) to calculate the fuzzy weight of each criterion evaluated by each evaluator, we get the calculating results as shown in Table 5. Based on (12), we rank the fuzzy weights with respect to each criterion $X_{i}$ evaluated by the evaluators, where $1 \leq i \leq 5$, we drop the fuzzy weights with the smallest ranking value and the largest ranking value. Then, we calculate the average of the remaining fuzzy weights using the addition operations and the division operations of fuzzy numbers. Finally, we can get the fuzzy weighted vector $W$, where $W=\left[\begin{array}{lllll}w_{1} & w_{2} & w_{3} & w_{4} & w_{5}\end{array}\right]^{t}, w_{i}$ denotes the average of the remaining fuzzy weights with respect to the $i$ th criterion, and $1 \leq i \leq 5$.

For example, let us consider the first row of Table 6 . Based on (12), we can see that $(3.3,4.3,5)>(3.2,4.2,5)>$ $(3,4,5)=(3,4,5)>(2.3,3 \cdot 3,4 \cdot 3)$. Because the fuzzy weights $(3.3,4.3,5)$ and $(2.3,3.3,4.3)$ have the largest ranking value and smallest ranking value, respectively, we drop the fuzzy weights $(3.3,4.3,5)$ and $(2.3,3.3,4.3)$, and then we can get the fuzzy weight $\widetilde{w}_{1}$ of criterion $X_{1}$ by calculating the average of the remaining fuzzy weights, shown as follows:

$$
\begin{aligned}
w_{1} & =[(3.2,4.2,5) \oplus(3,4,5) \oplus(3,4,5)] \oslash 3 \\
& =[(3.2,4.2,5) \oplus(3,4,5) \oplus(3,4,5)] \oslash(3,3,3) \\
& =(3.07,4.07,5) .
\end{aligned}
$$

Therefore, the fuzzy weight of criterion $X_{1}$ is $w_{1}$, where $w_{1}=$ $(3.07,4.07,5)$. Now we consider the second row of Table 6 . Based on (12), we can see that $(3.75,4.75,5)>(3.6,4.6,5)>$ $(3.1,4.1,5)>(2.9,3.9,4.9)>(2.8,3.8,4.8)$. Because the fuzzy weights $(3.75,4.75,5)$ and $(2.8,3.8,4.8)$ have the largest ranking value and smallest ranking value, respectively, we drop the fuzzy weights $(3.75,4.75,5)$ and $(2.8,3.8,4.8)$, and then we can get the fuzzy weight $w_{2}$ of criterion $X_{2}$ by calculating the average of the remaining fuzzyweights, shown as follows:

$$
\begin{aligned}
w_{2}= & {[(3.6,4.6,5) \oplus(3.1,4.1,5) \oplus(2.9,3.9,4.9)] } \\
& \oslash 3[(3.6,4.6,5) \oplus(3.1,4.1,5) \oplus(2.9,3.9,4.9)] \\
& \oslash(3,3,3) \\
= & (3.2,4.2,4.97) .
\end{aligned}
$$

In the same way, we can get the weights $w_{3}, w_{4}$, and $w_{5}$ of the criteria $X_{3}, X_{4}$, and $X_{5}$, respectively, where $w_{3}=(2.87$, $3.87,4.87), w_{4}=(2.98,3.98,4.97)$, and $w_{5}=(2.9,3.9,4.9)$. In this situation, the fuzzy weighted vector $W$ is as follows:

$$
W=\left[\begin{array}{l}
w_{1} \\
w_{2} \\
w_{3} \\
w_{4} \\
w_{5}
\end{array}\right]=\left[\begin{array}{l}
(3.07,4.07,5.00) \\
(3.20,4.20,4.97) \\
(2.87,3.87,4.87) \\
(2.98,3.98,4.97) \\
(2.90,3.90,4.90)
\end{array}\right]
$$

Step 2. Establish the fuzzy grade matrix. Each evaluator uses the fuzzy linguistic questionnaire shown in Table 3 to evaluate the performance of high school preceptors. Then, use (18) to calculate the fuzzy grade of each subcriterion of each preceptor evaluated by each evaluator, where the fuzzy grade represented by the fuzzy number $(k, m, n)$ should satisfy the rules: if $k<1$, then let $k=1$; if $n>5$, then let $n=5$. For example, assume that the fuzzy grades evaluated by the five evaluators are as shown in Tables 6, 7, 8, 9, and 10, respectively. Based on (7), we rank the fuzzy grades of a teacher with respect to a sub-criterion evaluated by the evaluators, drop the fuzzy grades with the smallest ranking value and the largest ranking value, and then calculate the average of the remaining fuzzy grades by using the addition operations and the division operations of fuzzy numbers to get the averaged fuzzy grade of the sub-criterion. In the same way we can get the averaged fuzzy grade of each sub-criterion of each teacher. For example, based on Tables 6, 7, 8, 9, and 10 and equation (12), we can rank the fuzzy grades of $A_{1}$ with respect to criterion $X_{11}$ evaluated by each evaluator, where the result is as follows: $(3.7,4.7,5)>(2.8,3.8,4.8)>(2.7,3.7,4.7)>$ $(2.5,3.5,4.5)=(2.5,3.5,4.5)$. Because the fuzzy weights $(3.7,4.7,5)$ and $(2.5,3.5,4.5)$ have the largest ranking value 
TABLE 4: The result after five evaluators till out the fuzzy linguistic questionnaires.

\begin{tabular}{|c|c|c|c|c|c|c|c|c|c|c|c|c|c|c|c|c|c|c|c|c|c|c|c|c|c|}
\hline \multirow{2}{*}{ Criterion } & \multicolumn{5}{|c|}{ Evaluator $E_{1}$} & \multicolumn{5}{|c|}{ Evaluator $E_{2}$} & \multicolumn{5}{|c|}{ Evaluator $E_{3}$} & \multicolumn{5}{|c|}{ Evaluator $E_{4}$} & \multicolumn{5}{|c|}{ Evaluator $E_{5}$} \\
\hline & $\mathrm{VL}$ & $\mathrm{L}$ & $\mathrm{M}$ & $\mathrm{H}$ & & VL & $\mathrm{L}$ & $\mathrm{M}$ & $\mathrm{H}$ & & & $\mathrm{L}$ & $\mathrm{M}$ & $\mathrm{H}$ & & & $\mathrm{L}$ & $\mathrm{M}$ & $\mathrm{H}$ & & VL & $\mathrm{L}$ & $\mathrm{M}$ & $\mathrm{H}$ & $\mathrm{VH}$ \\
\hline$X_{1}$ & 0 & 0 & 0 & 80 & 20 & 0 & 0 & 10 & 80 & 10 & 0 & 0 & 20 & 60 & & 0 & 0 & 0 & 70 & 30 & 0 & 0 & 80 & 10 & 10 \\
\hline$X_{2}$ & 0 & 0 & 10 & 70 & 20 & 0 & 0 & 0 & & & 0 & 0 & & & & & & 20 & & & & & 5 & & 80 \\
\hline$X_{3}$ & 0 & 20 & 80 & 0 & 0 & 0 & 0 & 20 & 70 & 10 & 0 & 0 & 0 & 70 & & 0 & 0 & 20 & 70 & 10 & 0 & 0 & 20 & 80 & 0 \\
\hline$X_{4}$ & 0 & 0 & 20 & 60 & 20 & 0 & 0 & 5 & 85 & 10 & 0 & 0 & 20 & 70 & 10 & 0 & 0 & 10 & 75 & 15 & 0 & 0 & 45 & 55 & 0 \\
\hline$X_{5}$ & 0 & 0 & 30 & 50 & 20 & 0 & 0 & 40 & 40 & 20 & 0 & 0 & 20 & 70 & 10 & 0 & 0 & 20 & 30 & 50 & 0 & 0 & 20 & 70 & 10 \\
\hline
\end{tabular}

TABLE 5: The fuzzy weight of each criterion evaluated by each evaluator.

\begin{tabular}{lccccc}
\hline Criterion & \multicolumn{3}{c}{ Evaluator } \\
& $E_{1}$ & $E_{2}$ & $E_{3}$ & $E_{4}$ & $(2.3,3.3,4.3)$ \\
\hline$X_{1}$ & $(3.2,4.2,5)$ & $(3,4,5)$ & $(3,4,5)$ & $(3.3,4.3,5)$ & $(3.75,4.75,5)$ \\
$X_{2}$ & $(3.1,4.1,5)$ & $(3.6,4.6,5)$ & $(2.8,3.8,4.8)$ & $(2.9,3.9,4.9)$ & $(2.8,3.8,4.8)$ \\
$X_{3}$ & $(1.8,2.8,3.8)$ & $(2.9,3.9,4.9)$ & $(3.3,4.3,5)$ & $(2.9,3.9,9)$ & $(2.55,3.55,4.55)$ \\
$X_{4}$ & $(3,4,5)$ & $(3.05,4.05,5)$ & $(2.9,3.9,4.9)$ & $(3.05,4.05,5)$ & $(2.9,3.9,4.9)$ \\
$X_{5}$ & $(2.9,3.9,4.9)$ & $(2.8,3.8,4.8)$ & $(2.9,3.9,4.9)$ & $(3.3,4.3,5)$ & \\
\hline
\end{tabular}

and smallest ranking value, respectively, we drop the fuzzy weights $(3.7,4.7,5)$ and $(2.5,3.5,4.5)$, and then we can get the fuzzy grade $g_{11,1}$ of preceptor $A_{1}$ with respect to sub-criterion $X_{11}$ by calculating the average of the remaining fuzzy weights, shown as follows:

$$
\begin{aligned}
g_{11,1}= & {[(2.8,3.8,4.8) \oplus(2.7,3.7,4.7) \oplus(2.5,3.5,4.5)] \oslash 3 } \\
= & {[(2.8,3.8,4.8) \oplus(2.7,3.7,4.7) \oplus(2.5,3.5,4.5)] } \\
& \oslash(3,3,3)=(2.67,3.67,4.67) .
\end{aligned}
$$

Therefore, the fuzzy grade of preceptor $A_{1}$ with respect to sub-criterion $X_{11}$ is $g_{11,1}$, where $g_{11,1}=(2.67,3.67,4.67)$. Then, based on (7), we can rank the fuzzy grades of preceptor $A_{2}$ with respect to criterion $X_{12}$ evaluated by each evaluator. The result is shown as follows: $(3.7,4.7,5)>(3.2,4.2,5)>$ $(2.6,3.6,4.6)=(2.6,3.6,4.6)>(2.3,3.3,4.3)$. Because the fuzzy weights $(3.7,4.7,5)$ and $(2.3,3.3,4.3)$ have the largest ranking value and smallest ranking value, respectively, we drop the fuzzy weights $(3.7,4.7,5)$ and $(2.3,3.3,4.3)$, and then we can get the fuzzy grade $g_{12,1}$ of preceptor $A_{1}$ with respect to sub-criterion $X_{12}$ by calculating the average of the remaining fuzzy weights shown as follows:

$$
\begin{aligned}
g_{12,1} & =[(3.2,4.2,5) \oplus(2.6,3.6,4.6) \oplus(2.6,3.6,4.6)] \oslash 3 \\
& =[(3.2,4.2,5) \oplus(2.6,3.6,4.6)(2.6,3.6,4.6)] \oslash(3,3,3) \\
& =(2.8,3.8,4.73)
\end{aligned}
$$

In the same way, we can get the fuzzy grade of each teacher with respect to each sub-criterion to derive the averaged fuzzygrade table shown in Table 11. Then, we apply the simplified fuzzy numbers addition operations and division operations to the averaged fuzzy grade table shown in Table 11 to get the fuzzy grade of each teacher with respect to each criterion. Finally, we can get the fuzzy grade matrix $G$ defined as follows:

$$
G=\left[\begin{array}{ccccc}
\frac{A}{X} & X_{1} & X_{2} & \cdots & X_{k} \\
A_{1} & g_{11} & g_{12} & \cdots & g_{1 k} \\
A_{2} & g_{21} & g_{22} & \cdots & g_{2 k} \\
\vdots & \vdots & \ddots & \cdots & \vdots \\
A_{n} & g_{n 1} & g_{n 2} & \cdots & g_{n k}
\end{array}\right],
$$

where $g_{i j}$ denotes the fuzzy grade of the $i$ th preceptor $A_{i}$ with respect to the $j$ th criterion $X_{j}$, where $1 \leq i \leq n, 1 \leq j \leq k$ and $n$ denotes the number of preceptors, and $k$ denotes the number of criteria. For example, based on Table 11, we can calculate $g_{11}$ as follows:

$$
\begin{aligned}
g_{11}=( & \frac{(2.67+2.8+2.97+2.33+2.72+2.38+2.83+1.85+2.93)}{9}, \\
& \frac{(3.67+3.8+3.97+3.33+3.72+3.38+3.83+2.85+3.93)}{9}, \\
& \left.\frac{(4.67+4.73+4.92+4.33+4.5+4.38+4.75+3.85+4.83)}{9}\right) \\
= & (2.61,3.61,4.55) .
\end{aligned}
$$

In the same way, we can get the fuzzy grade matrix $G$ as follows: 


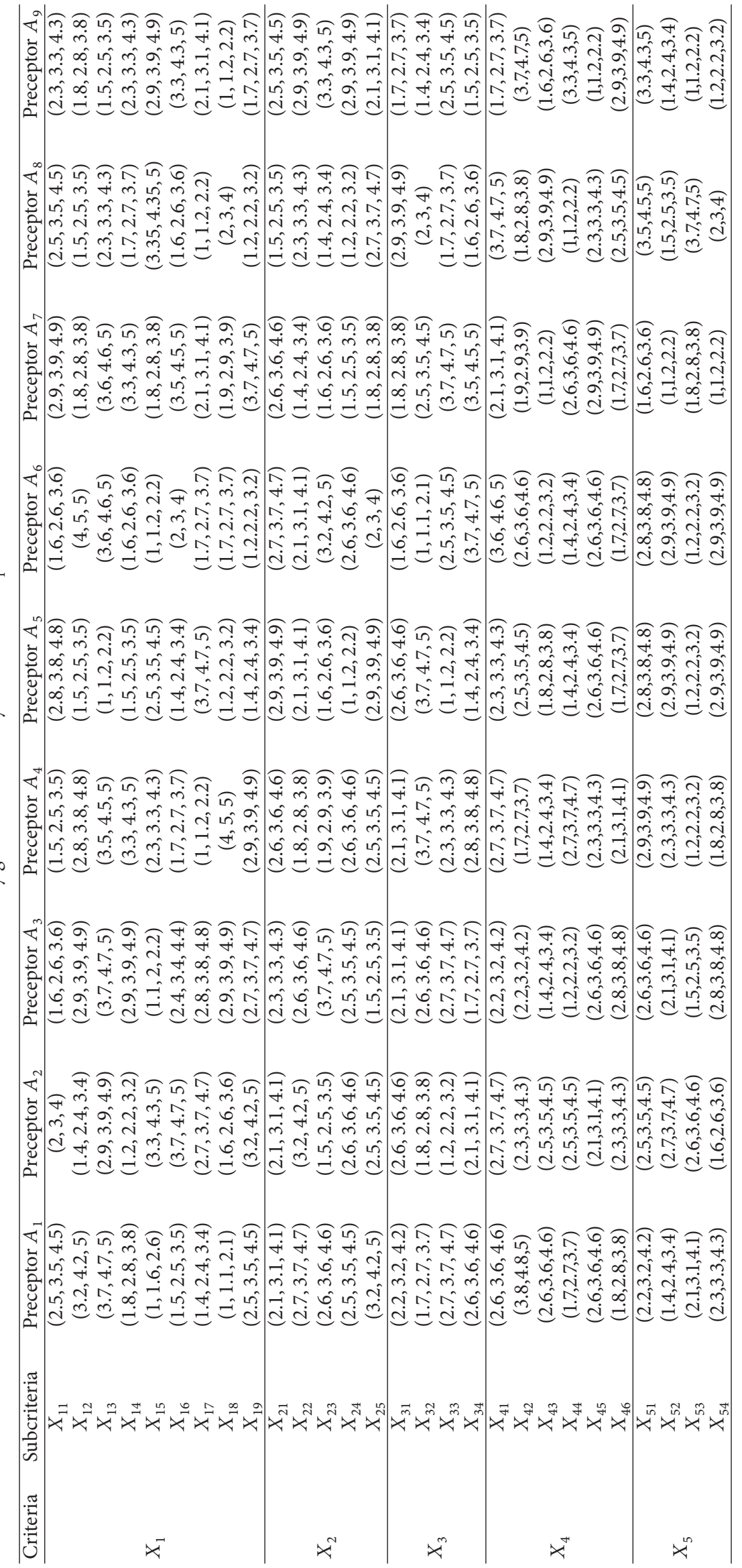




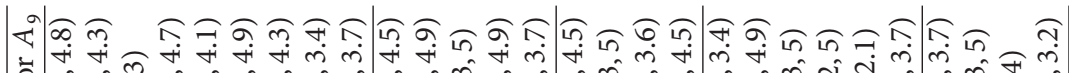
क्ष

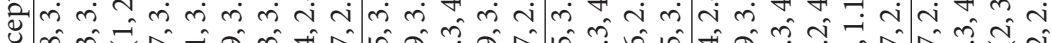

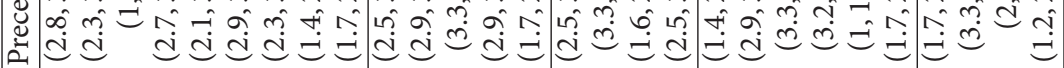

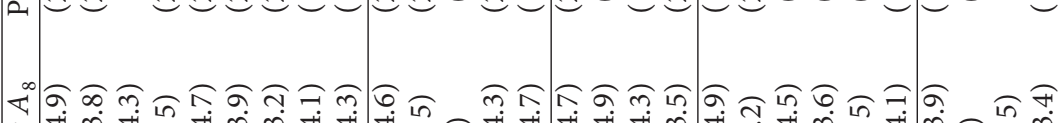

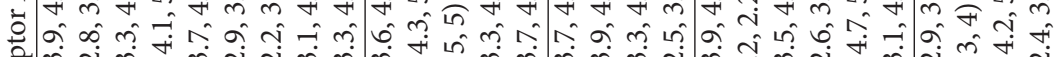

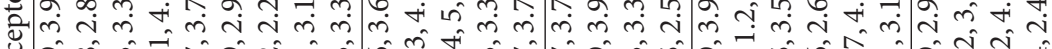

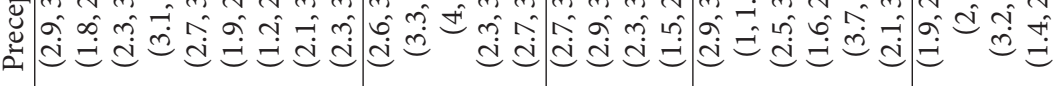

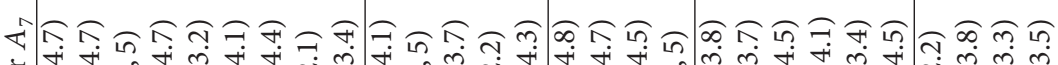
क्षे

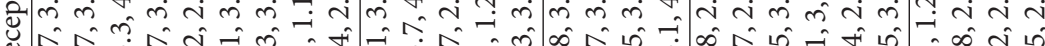

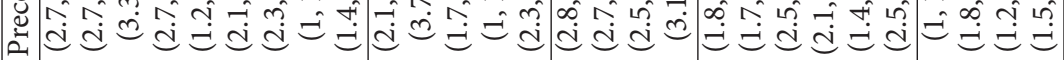

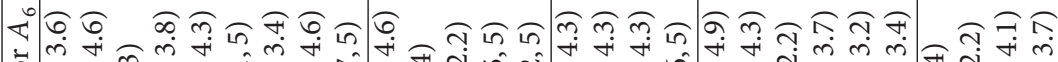

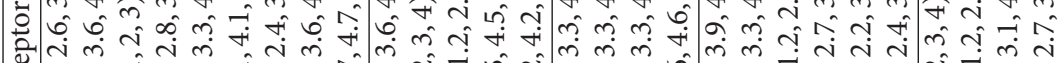

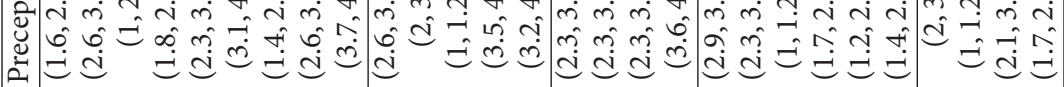

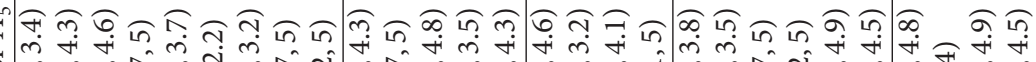

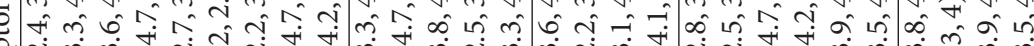

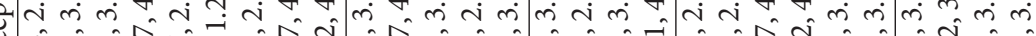

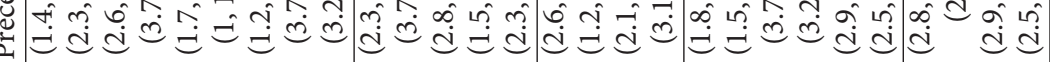

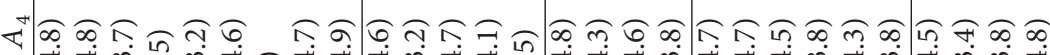

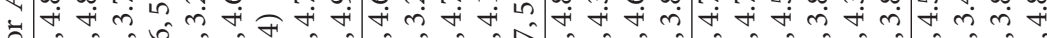
की

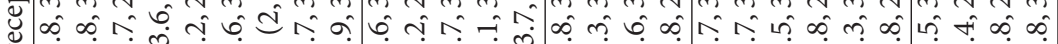

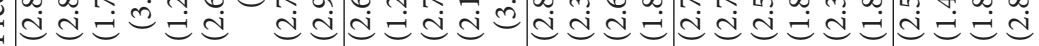

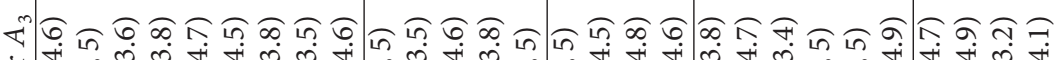
oै

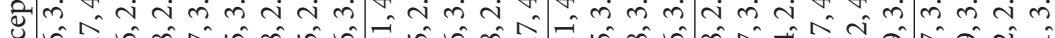

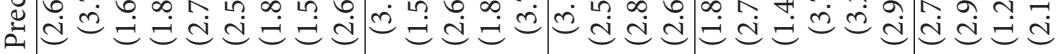

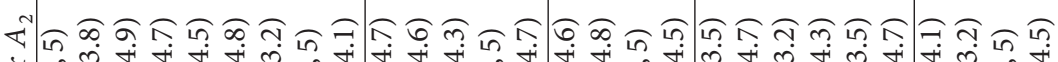

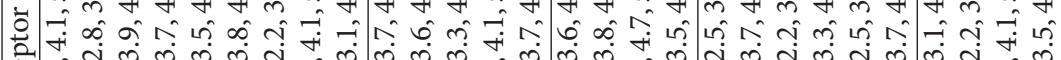

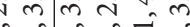
氙

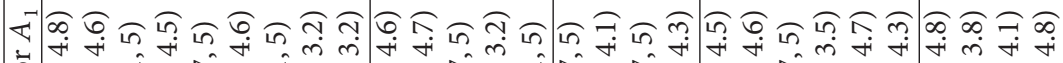

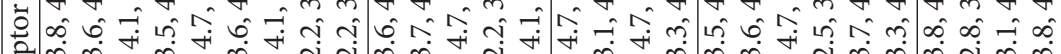

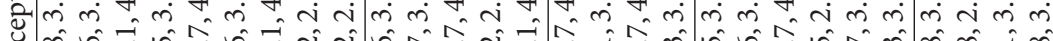

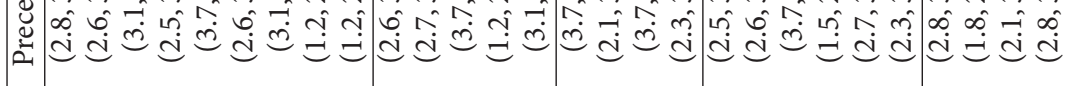

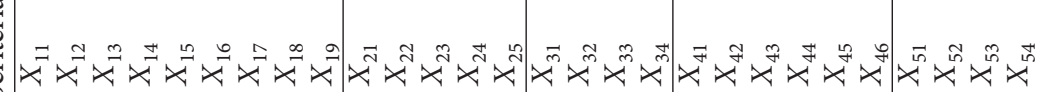

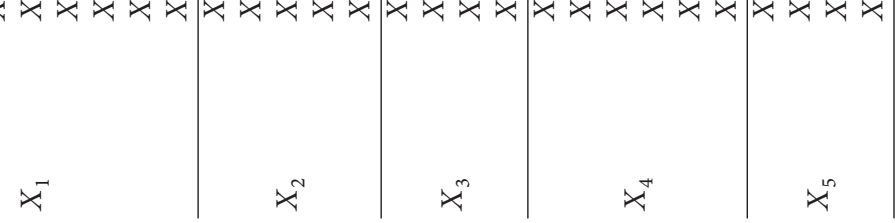




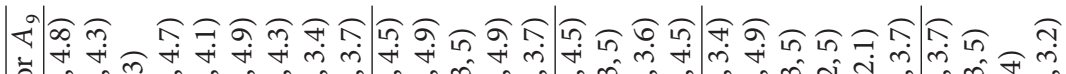
कै

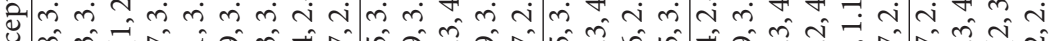

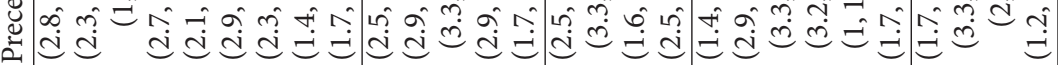

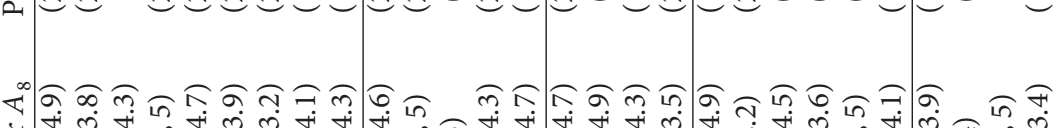

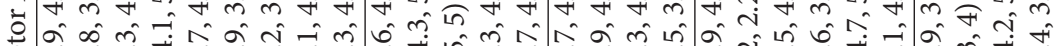

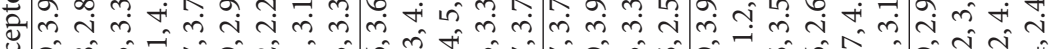

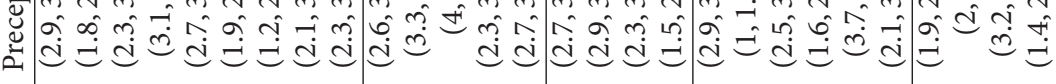

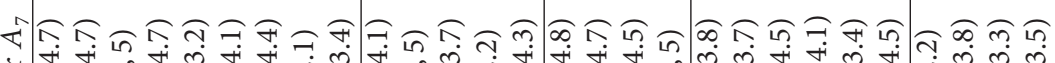

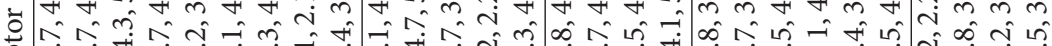

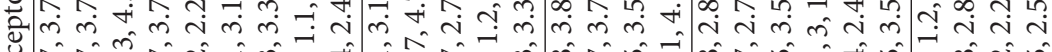

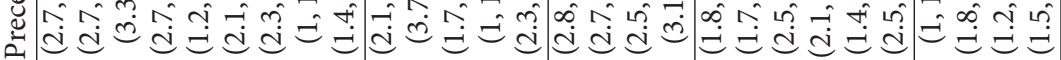

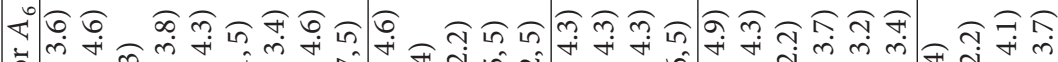

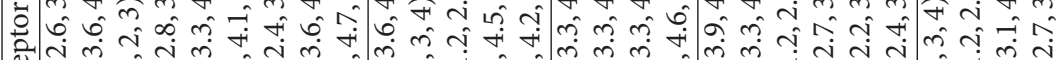
党

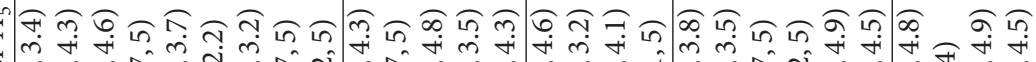

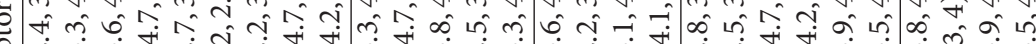

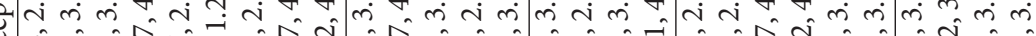

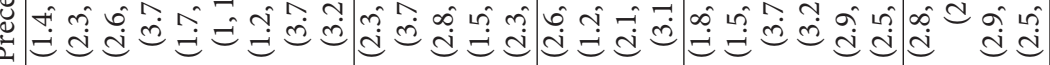

स

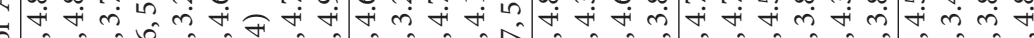
की कo no

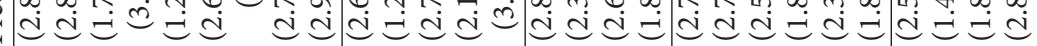

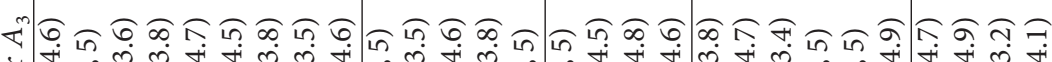
to 00 की

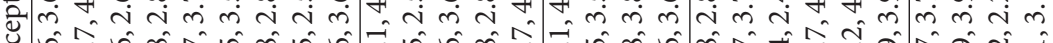

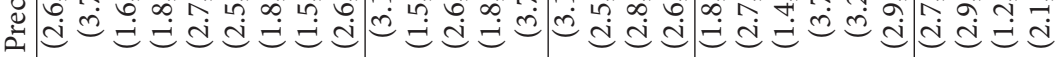

제

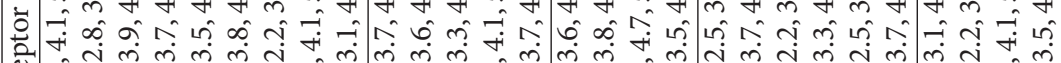
mit 氙

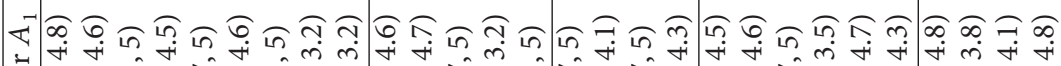

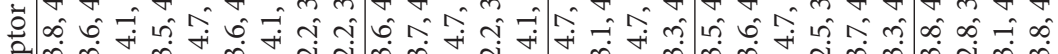

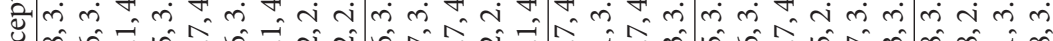

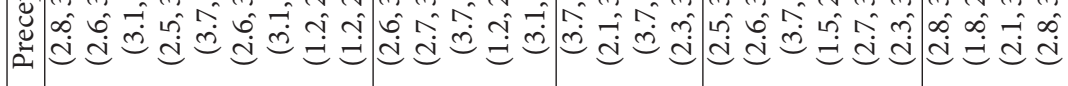

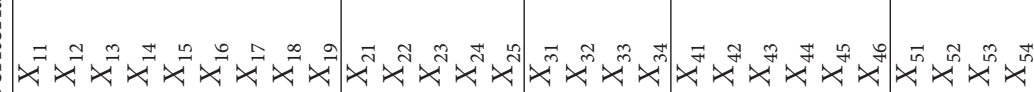

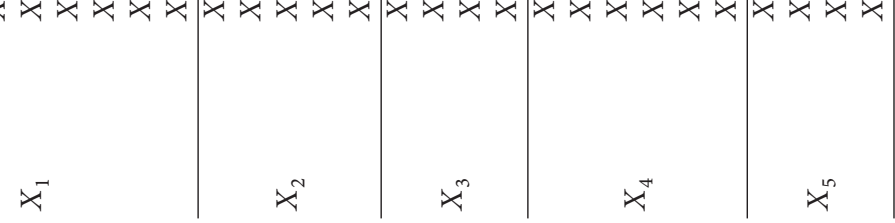




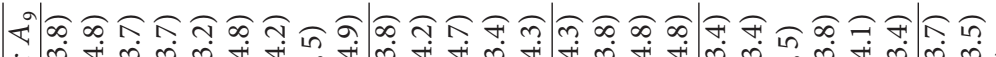

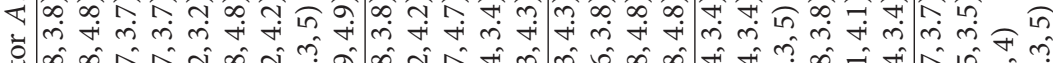
की

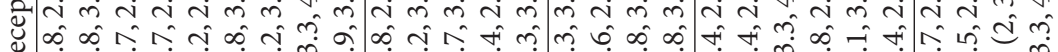

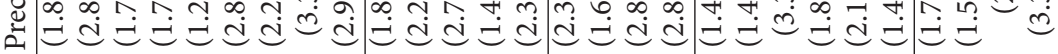

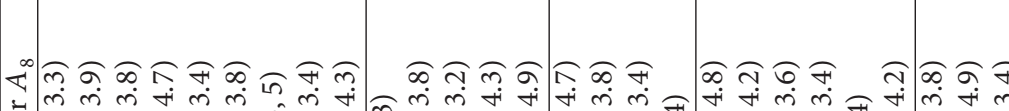

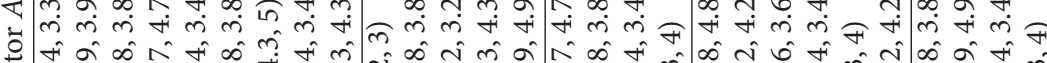

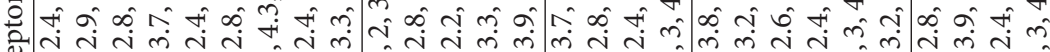

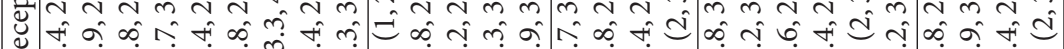

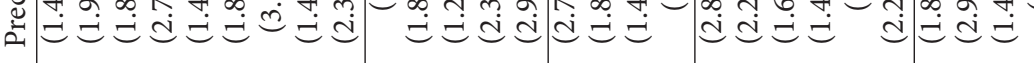

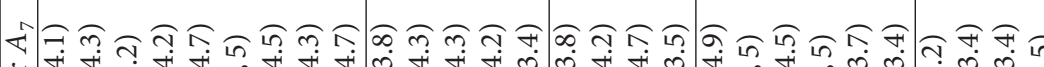
क्षै

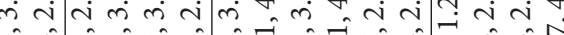

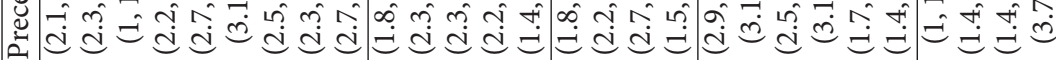

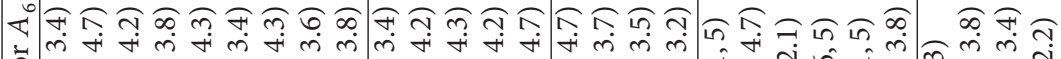

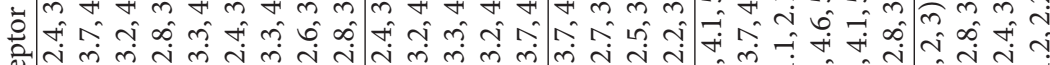

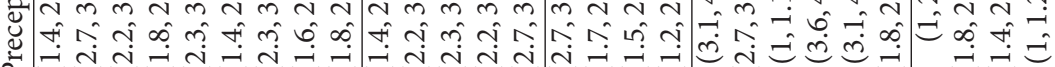

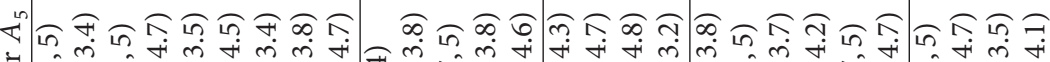

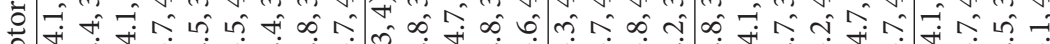

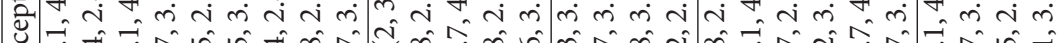

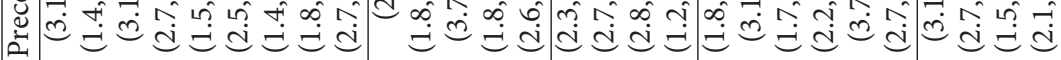

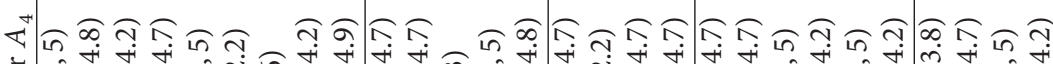
t) $\Rightarrow$ स

m小

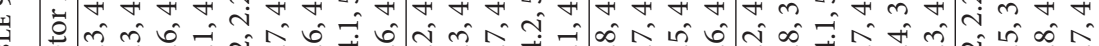

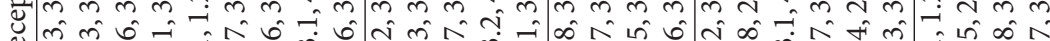

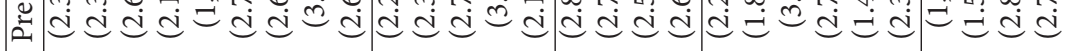

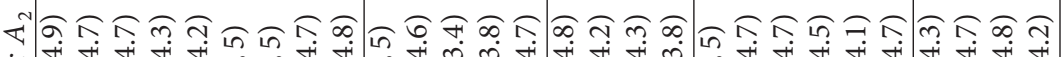

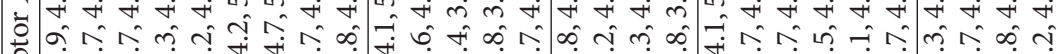
a

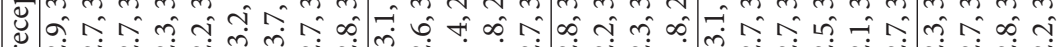

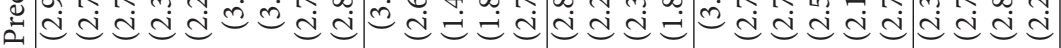

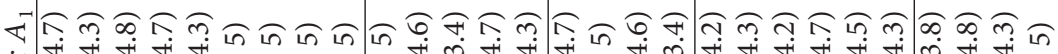

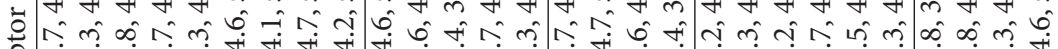

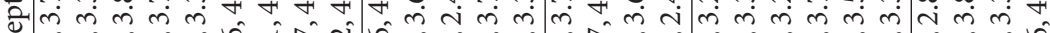

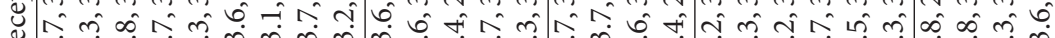
id d d d d

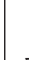

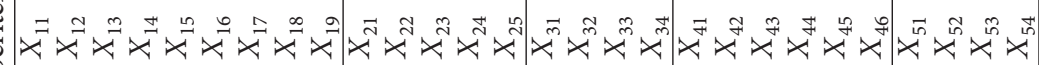




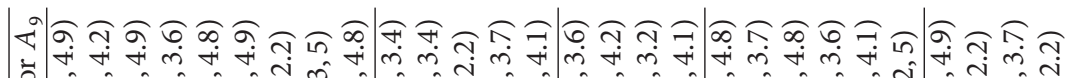

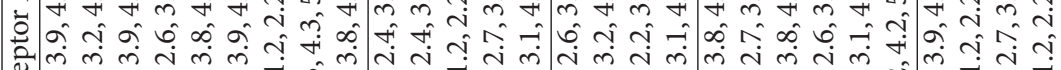
空

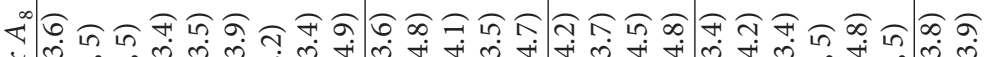

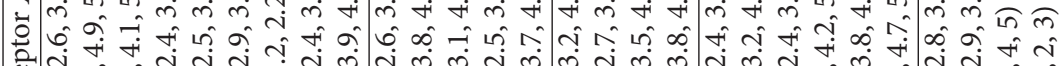

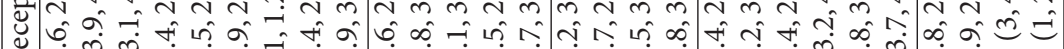

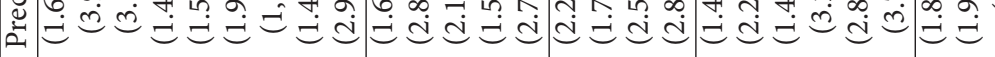

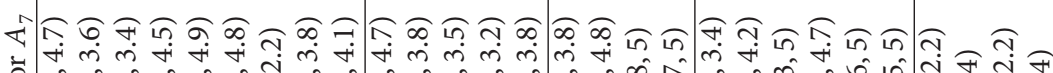
कै मी

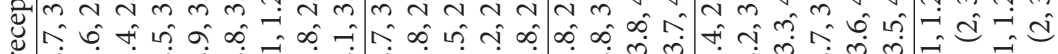

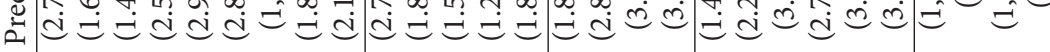

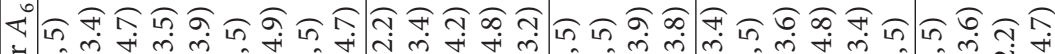

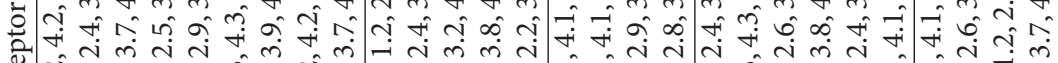
tin पूँ ती ती की

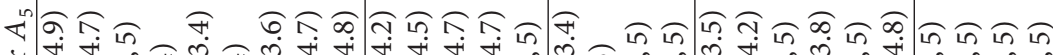

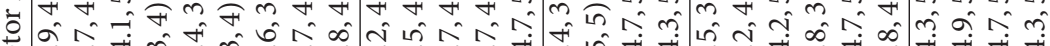

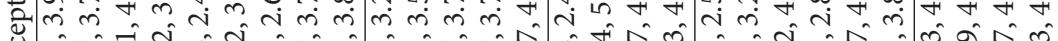

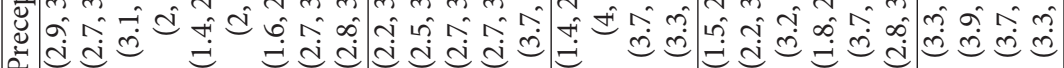

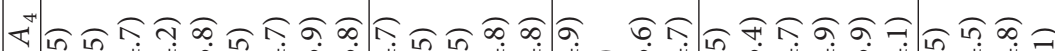
tै

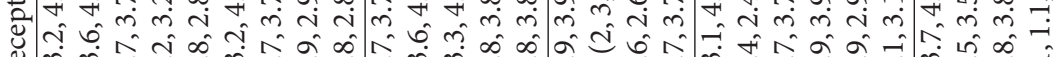
离

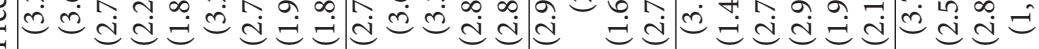

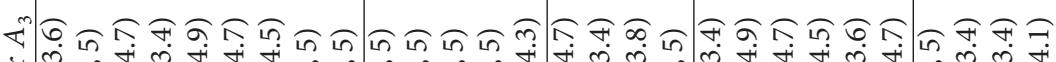
oै

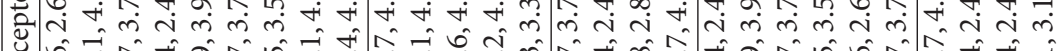

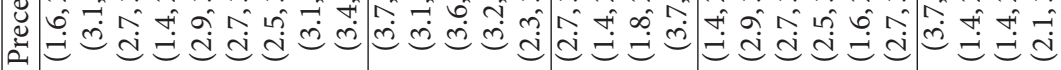

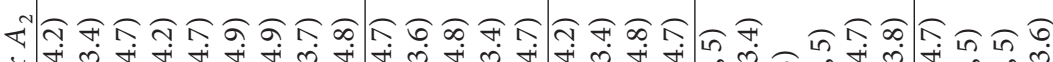

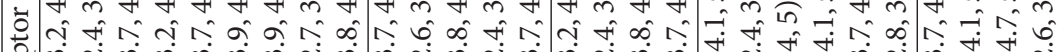

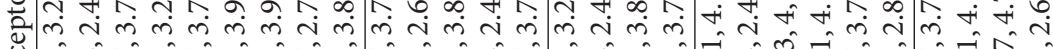

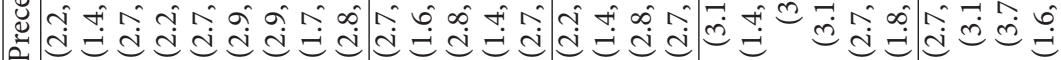

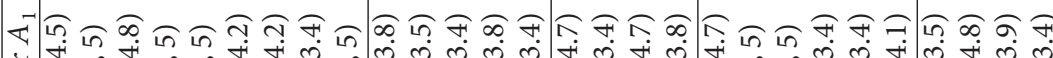

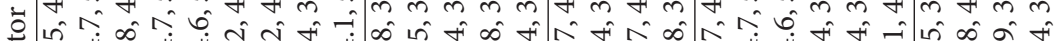
की मी

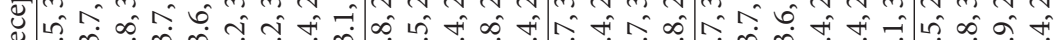
离

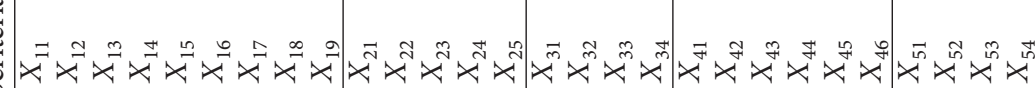




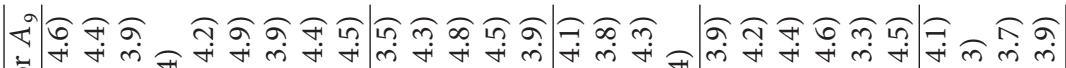
कै

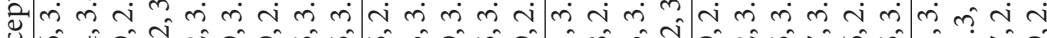

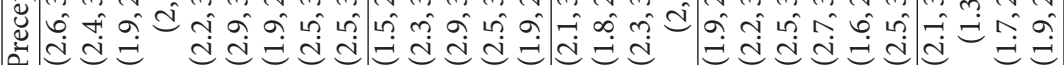

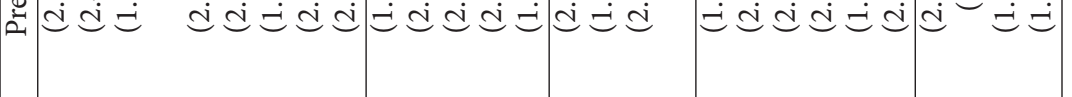

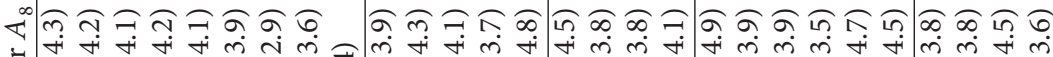

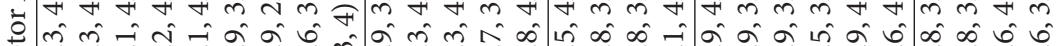

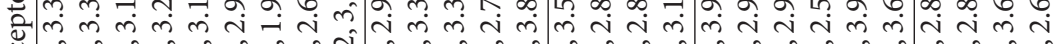

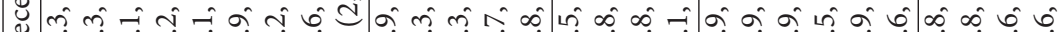
च.

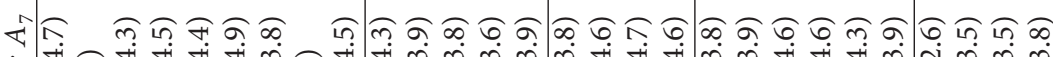

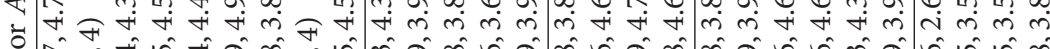

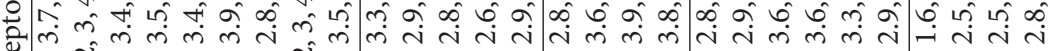

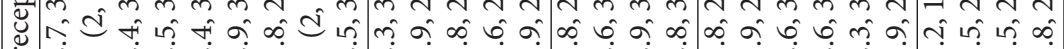

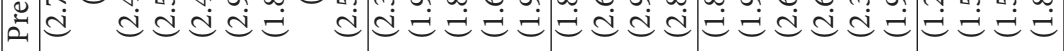

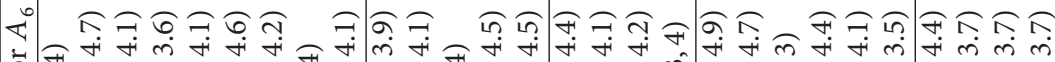

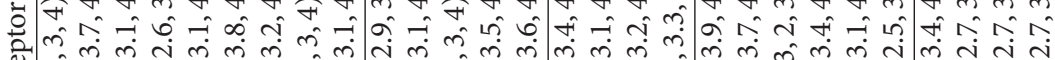

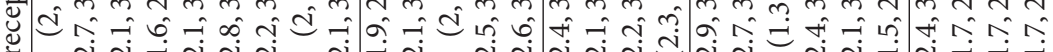

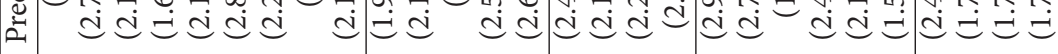

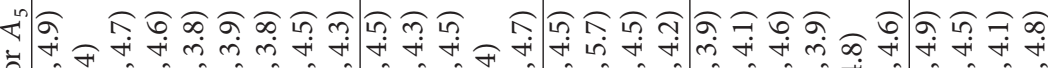

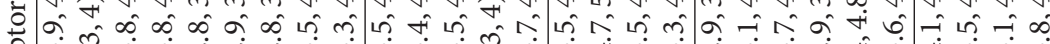

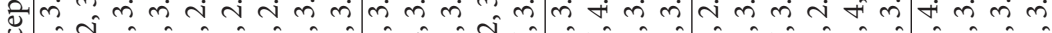

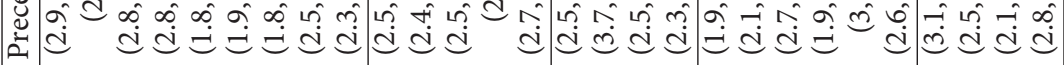

स +

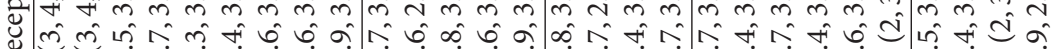

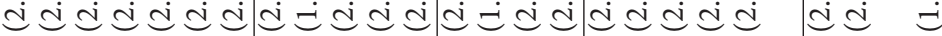

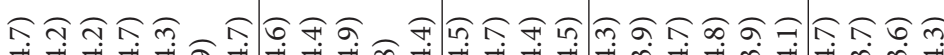

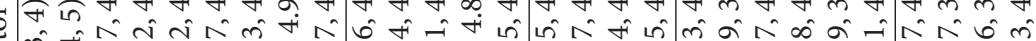

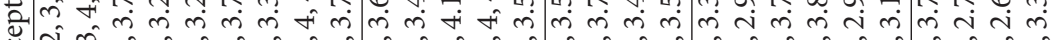

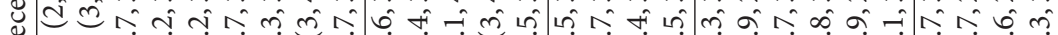

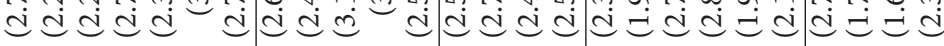

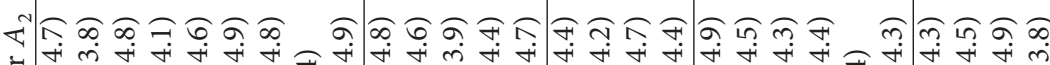
कै मी की की -

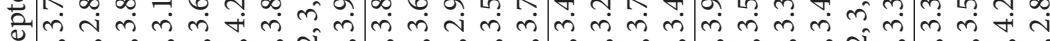

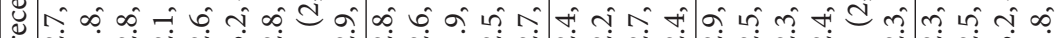

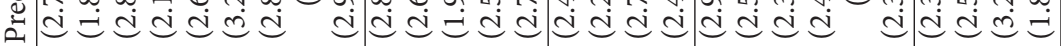

ব)

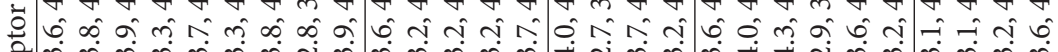

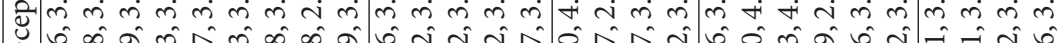

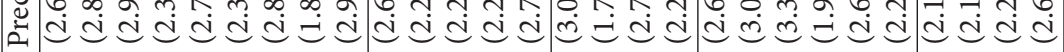
$=$ 


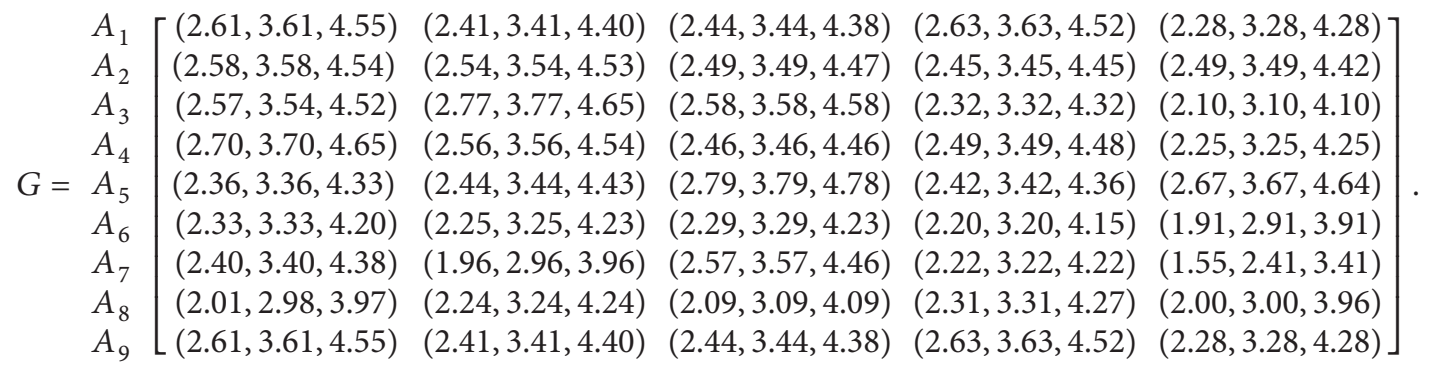

Step 3. Calculate the total fuzzy grade vector $R$, where

$$
\begin{aligned}
R & =G \otimes W=\left[\begin{array}{cccc}
g_{11} & g_{12} & \cdots & g_{1 k} \\
g_{21} & g_{22} & \cdots & g_{2 k} \\
\vdots & \vdots & \ddots & \vdots \\
g_{n 1} & g_{n 2} & \cdots & g_{n k}
\end{array}\right] \\
& \otimes\left[\begin{array}{c}
w_{1} \\
w_{2} \\
\vdots \\
w_{k}
\end{array}\right]=\left[\begin{array}{c}
g_{11} \otimes w_{1} \oplus g_{12} \otimes w_{2} \oplus \cdots \oplus g_{1 k} \otimes w_{k} \\
g_{21} \otimes w_{1} \oplus g_{22} \otimes w_{2} \oplus \cdots \oplus g_{2 k} \otimes w_{k} \\
\vdots \\
g_{n 1} \otimes w_{1} \oplus g_{n 2} \otimes w_{2} \oplus \cdots \oplus g_{n k} \otimes w_{k}
\end{array}\right] \\
& =\left[\begin{array}{c}
R_{1} \\
R_{2} \\
R_{3} \\
R_{4}
\end{array}\right],
\end{aligned}
$$

where $R_{i}$ denotes the total fuzzy grade of the $i$ th preceptor $A_{i}$ and $1 \leq i \leq n$. For example, based on the fuzzy weighted vector $W$ obtained in Step 1, the fuzzy grade matrix $G$ obtained in Step 2 and (28), we can calculate the total fuzzy grade $R_{1}$ of teacher $A_{1}$ as follows:

$$
\begin{aligned}
R_{1}= & (2.61,3.61,4.55) \otimes(3.07,4.07,5) \oplus(2.61,3.61,4.55) \\
& \otimes(3.2,4.2,4.97) \oplus(2.61,3.61,4.55) \otimes(2.87,3.87,4.87) \\
& \oplus(2.98,3.98,4.97) \otimes(2.98,3.98,4.97) \\
& \oplus(2.61,3.61,4.55)(2.9,3.9,4.9) \\
= & (37.18,69.57,109.39) .
\end{aligned}
$$

In the same way, we can get the total fuzzy grade vector $R$ shown as follows:

$$
R=\left[\begin{array}{l}
R_{1} \\
R_{2} \\
R_{3} \\
R_{4} \\
R_{5} \\
R_{6} \\
R_{7} \\
R_{8} \\
R_{9}
\end{array}\right]=\left[\begin{array}{c}
(37.18,69.57,109.39) \\
(37.72,70.29,110.76) \\
(37.16,69.4,109.58) \\
(37.49,69.57,110.62) \\
(38.02,70.72,111.35) \\
(33.02,64.02,102.41) \\
(32.13,62.30,100.98) \\
(32.02,62.57,101.47) \\
(32.58,62.84,101.55)
\end{array}\right],
$$

$$
\begin{aligned}
& R_{1}^{*}=\left(\frac{37.18}{120}, \frac{69.57}{120}, \frac{109.39}{120}\right), \\
& R_{2}^{*}=\left(\frac{37.72}{120}, \frac{70.29}{120}, \frac{110.76}{120}\right), \\
& R_{3}^{*}=\left(\frac{37.16}{120}, \frac{69.40}{120}, \frac{109.58}{120}\right), \\
& R_{4}^{*}=\left(\frac{37.49}{120}, \frac{69.57}{120}, \frac{110.62}{120}\right), \\
& R_{5}^{*}=\left(\frac{38.02}{120}, \frac{70.72}{120}, \frac{111.35}{120}\right), \\
& R_{6}^{*}=\left(\frac{33.02}{120}, \frac{64.02}{120}, \frac{102.41}{120}\right), \\
& R_{7}^{*}=\left(\frac{32.13}{120}, \frac{62.30}{120}, \frac{100.98}{120}\right), \\
& R_{8}^{*}=\left(\frac{32.02}{120}, \frac{62.57}{120}, \frac{101.47}{120}\right), \\
& R_{9}^{*}=\left(\frac{32.58}{120}, \frac{62.84}{120}, \frac{101.55}{120}\right),
\end{aligned}
$$

Step 4. Based on (12), calculate the ranking value $S\left(R_{i}\right)$ of the fuzzy grade $R_{i}$, where $1 \leq i \leq n$. The larger the value of $S\left(R_{i}\right)$, the better the ranking of $R_{i}$ and the better the choice of preceptor $A_{i}$, where $1 \leq i \leq n$ and $n$ denotes the number of teachers. For example, after applying (12) to rank the fuzzy numbers $R_{1}, R_{2}, R_{3}, R_{4}, R_{5}, R_{6}, R_{7}, R_{8}$, and $R_{9}$ of the fuzzy grade vector $R$ obtained in Step 3 , we can get the ranking results as shown in Table 12. We can see that $R_{5}>R_{2}>R_{4}>$ $R_{1}>R_{3}>R_{6}>R_{9}>R_{7}>R_{8}$. Because $R_{5}$ has the largest ranking value, preceptor $A_{5}$ is the best choice.

\section{Conclusions}

In this paper, we proposed a new centroid index method for ranking fuzzy numbers. First we briefly introduce some existing centroid index ranking methods of fuzzy numbers. Then we propose a new method to evaluate the efficiency of 
TABLE 12: Ranking values of the total fuzzy grades.

\begin{tabular}{ccccc}
\hline & $x_{R_{i}}^{*}$ & $y_{R_{i}}^{* s}$ & $s_{R_{i}^{*}}$ & Ranking value $s\left(R_{i}^{*}\right)$ \\
\hline$R_{1}^{*}$ & 0.6003 & 0.9049 & 0.2462 & 0.9644 \\
$R_{2}^{*}$ & 0.6076 & 0.9038 & 0.2492 & 0.9660 \\
$R_{3}^{*}$ & 0.6003 & 0.9046 & 0.2471 & 0.9641 \\
$R_{4}^{*}$ & 0.6046 & 0.9037 & 0.2497 & 0.9647 \\
$R_{5}^{*}$ & 0.6113 & 0.9035 & 0.2502 & 0.9669 \\
$R_{6}^{*}$ & 0.5540 & 0.9084 & 0.2367 & 0.9527 \\
$R_{7}^{*}$ & 0.5427 & 0.9090 & 0.2351 & 0.9500 \\
$R_{8}^{*}$ & 0.5445 & 0.9083 & 0.2371 & 0.9498 \\
$R_{9}^{*}$ & 0.5471 & 0.9089 & 0.2355 & 0.9511 \\
\hline
\end{tabular}

school preceptors based on fuzzy number arithmetic operations. The proposed method can overcome the drawbacks of the other methods.

\section{Acknowledgment}

The authors would like to express their sincere appreciation to the Department of Mathematics, Islamic Azad University, Urmia Branch in Iran for their cooperation.

\section{References}

[1] G. Bortolan and R. Degani, "A review of some methods for ranking fuzzy subsets," Fuzzy Sets and Systems, vol. 15, no. 1, pp. $1-19,1985$.

[2] S. J. Chen and C. L. Hwang, Fuzzy Multiple Attribute Decision Making, Springer, Berlin, Germany, 1993.

[3] S. J. Chen and S. M. Chen, "A new method for handling multicriteria fuzzy decision-making problems using FN-IOWA operators," Cybernetics and Systems, vol. 34, no. 2, pp. 109-137, 2003.

[4] J. R. Chang, C. H. Cheng, and C. Y. Kuo, "Conceptual procedure for ranking fuzzy numbers based on adaptive two dimensions dominance," Soft Computing, vol. 10, no. 3, pp. 74-103, 2006.

[5] D. Dubois and H. Prade, "Operations on fuzzy numbers," International Journal of Systems Science, vol. 9, no. 6, pp. 613626, 1978.

[6] R. Saneifard, T. Allahviranloo, F. Hosseinzadeh, and N. Mikaeilvand, "Euclidean ranking DMUs with fuzzy data in DEA," Applied Mathematical Sciences, vol. 60, pp. 2989-2998, 2007.

[7] R. Saneifard and R. Ezzati, "Defuzzification through a bisymmetrical weighted function," Australian Journal of Basic and Applied Sciences, vol. 4, no. 10, pp. 4976-4984, 2010.

[8] R. Saneifard, "Ranking L-R fuzzy numbers with weighted averaging based on levels," International Journal of Industrial Mathematics, vol. 2, pp. 163-1173, 2009.

[9] R. Ezzati and R. Saneifard, "A new approach for ranking of fuzzy numbers with continuous weighted quasi-arithmetic means," Mathematical Sciences, vol. 2, pp. 143-158, 2010.

[10] Y.-M. Wang, J.-B. Yang, D.-L. Xu, and K.-S. Chin, "On the centroids of fuzzy numbers," Fuzzy Sets and Systems, vol. 157, no. 7, pp. 919-926, 2006.

[11] C.-H. Cheng, "A new approach for ranking fuzzy numbers by distance method," Fuzzy Sets and Systems, vol. 95, no. 3, pp. 307317, 1998.
[12] T.-C. Chu and C.-T. Tsao, "Ranking fuzzy numbers with an area between the centroid point and original point," Computers \& Mathematics with Applications, vol. 43, no. 1-2, pp. 111-117, 2002. 


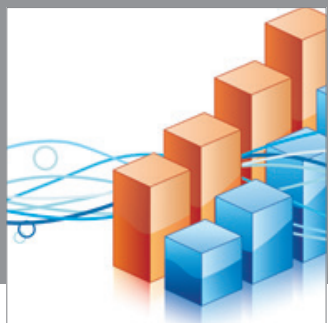

Advances in

Operations Research

mansans

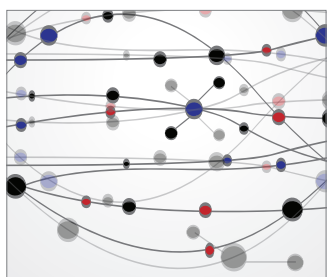

The Scientific World Journal
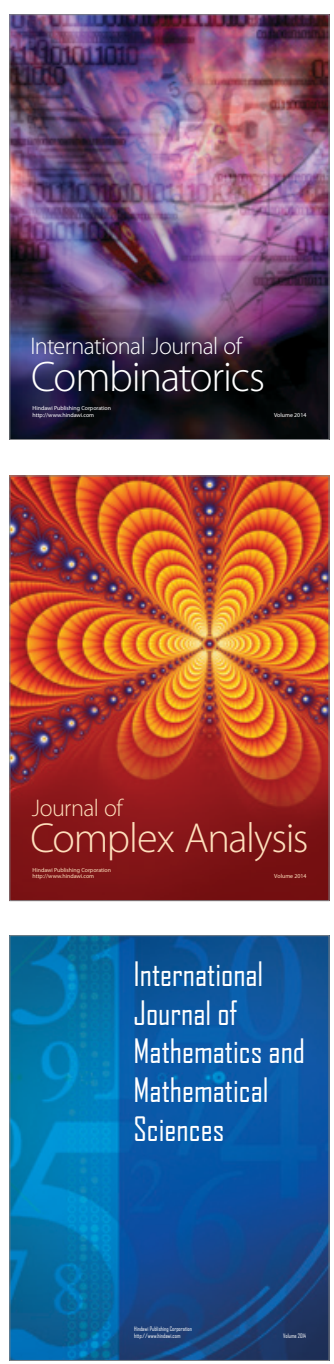
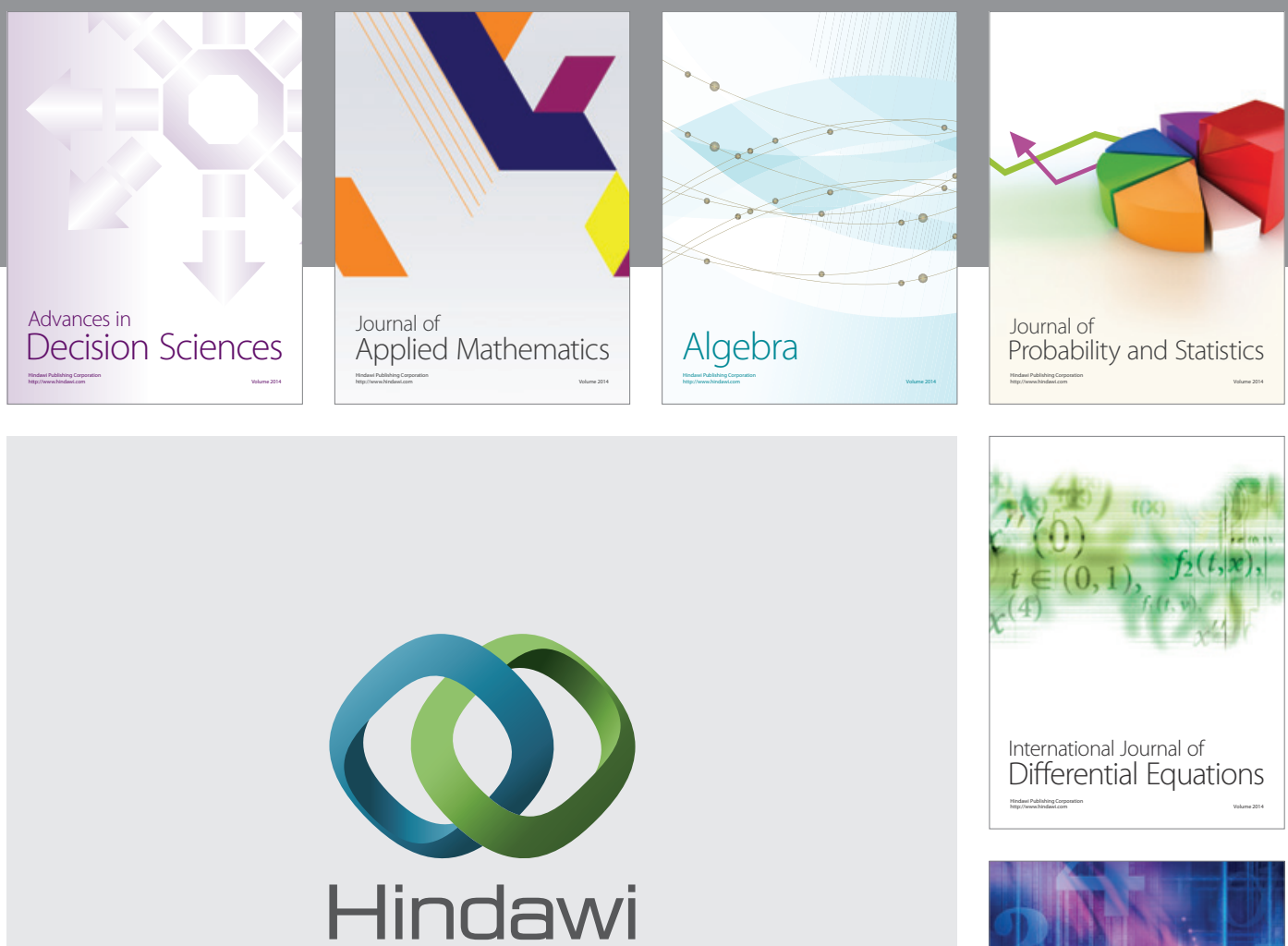

Submit your manuscripts at http://www.hindawi.com
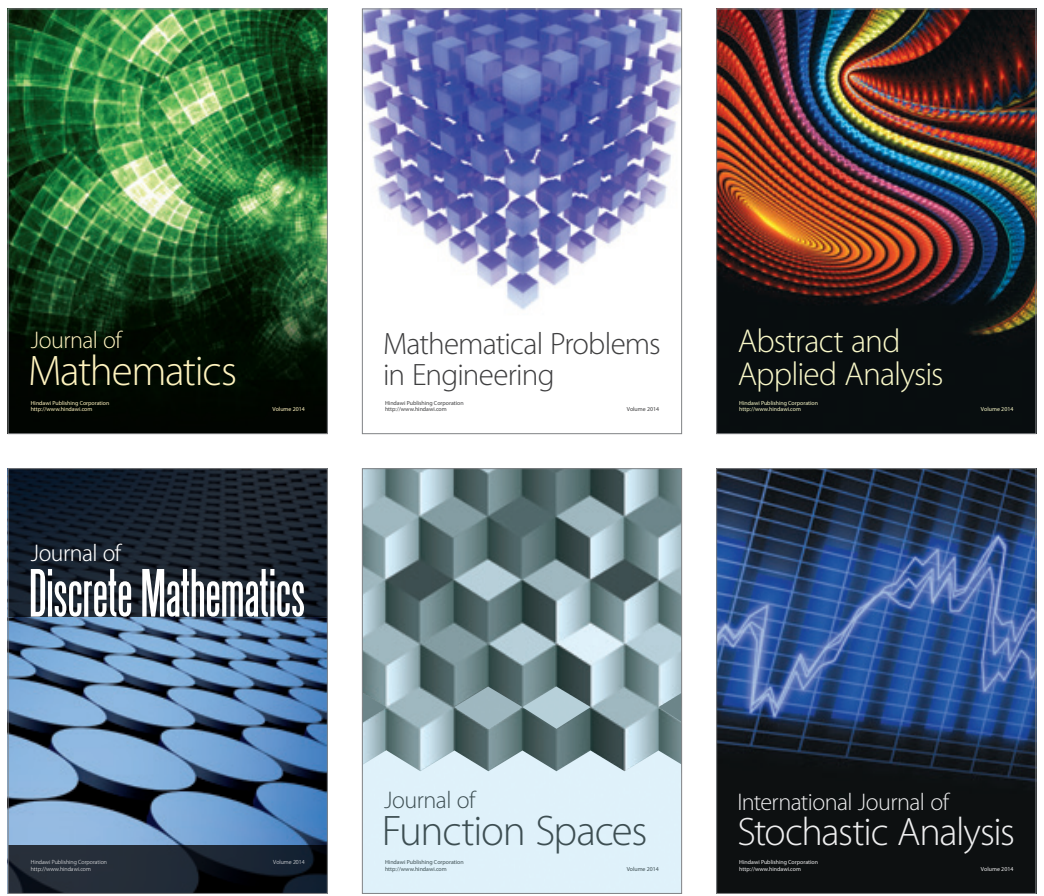

Journal of

Function Spaces

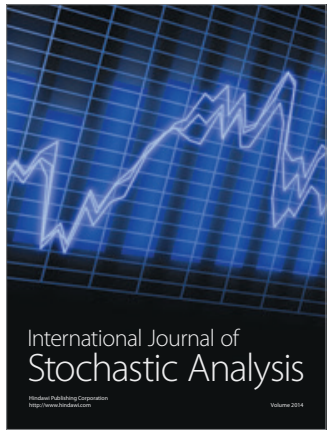

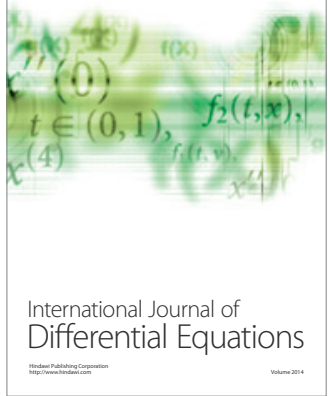
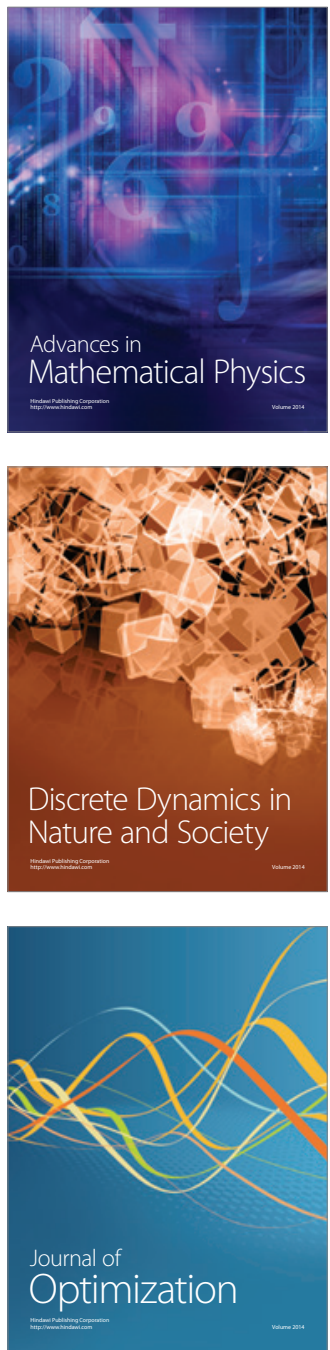